\title{
Biological and Biomimetic Materials—Honoring Prof. A. Darvizeh
}

\author{
Hamed Rajabi ${ }^{1}$. David Taylor ${ }^{2}$ Stanislav Gorb ${ }^{1}$ \\ Published online: 11 April 2021 \\ (c) The Author(s), under exclusive licence to Springer-Verlag GmbH, DE part of Springer Nature 2021
}

\section{Introduction}

This Thematic Series is dedicated to the memory of Professor Abolfazl Darvizeh (1951-2021) (Fig. 1). He believed passionately that "life is a complicated engineering phenomenon and, hence, any investigation on living systems should be accomplished within the framework of engineering principles and processes." He hoped that more studies on living systems would reveal more of their inherent technological complexities. We agree with that, which is why we decided to organize this Thematic Series.

The Thematic Series "Biological and Biomimetic Materials-Honoring Prof. A. Darvizeh" covers a wide range of studies from fundamental research to practical applications. We invited a number of well-known scholars in the field to contribute articles that focus on understanding the complexities of biological materials and structures and their practical applications.

We would like to thank the authors for their excellent contributions to this Thematic Series and appreciate their support and commitment. We thank the continuous support of Applied Physics A, Springer and its staff, who made this Thematic Series possible. We would also like to thank reviewers who kindly supported us by assessing the submitted manuscripts and helped to improve the quality of the whole Thematic Series.

Hamed Rajabi

hrajabi@zoologie.uni-kiel.de; harajabi@hotmail.com

1 Functional Morphology and Biomechanics, Institute of Zoology, Kiel University, Kiel, Germany

2 Trinity Centre for Bioengineering, Trinity College Dublin, Dublin, Ireland

\section{Abolfazl Darvizeh: a distinguished scientist, a remarkable teacher, a committed citizen}

Professor Abolfazl Darvizeh passed away on March 6, 2021, in Rasht. His unexpected death came as a shock to his many students, colleagues and friends. Although he had retired from his chair position in Mechanical Engineering at the University of Guilan, he was still quite active in teaching, research and administration, being the Chancellor of Ahrar Institute of Technology and Higher Education and holding a chair position in Mechanical Engineering at Islamic Azad University, Bandar Anzali Branch.

Abolfazl Darvizeh was born in 1951 in Tehran, Iran. He studied Mechanical Engineering at Iran University of Science and Technology. In 1982, he received his doctorate in Mechanical Engineering from the University of Manchester Institute of Science and Technology (UMIST) for his research on high rate electrical discharge compaction of metal-based powders in the group of Prof. Salim Al-Hassani. Quickly after graduation, he came back to Iran, although the country was suffering from economic hardship and facing major shortages, due to Iran-Iraq War (1980-1988). He was committed to make a difference.

From 1983 to 1995 , he contributed to teaching and research at the University of Guilan, Sharif University of Technology and K.N.T University of Technology. From 1995 to 2002, he worked as an Associate Professor in the Department of Mechanical Engineering at the University of Guilan, where he also served as the Dean of Faculty of Engineering (1990-1991), Head of the Department of Mechanical Engineering (1985-1991), Pro-Vice-Chancellor for Research (1995-2003). He was promoted to professor in 2002 .

Abolfazl Darvizeh's research significantly contributed to the field of high energy rate forming of materials. He was one of the pioneers of this field in Iran and played a key role in establishing this research area in the country. His research specifically focused on high rate forming techniques, including explosive forming, electromagnetic 


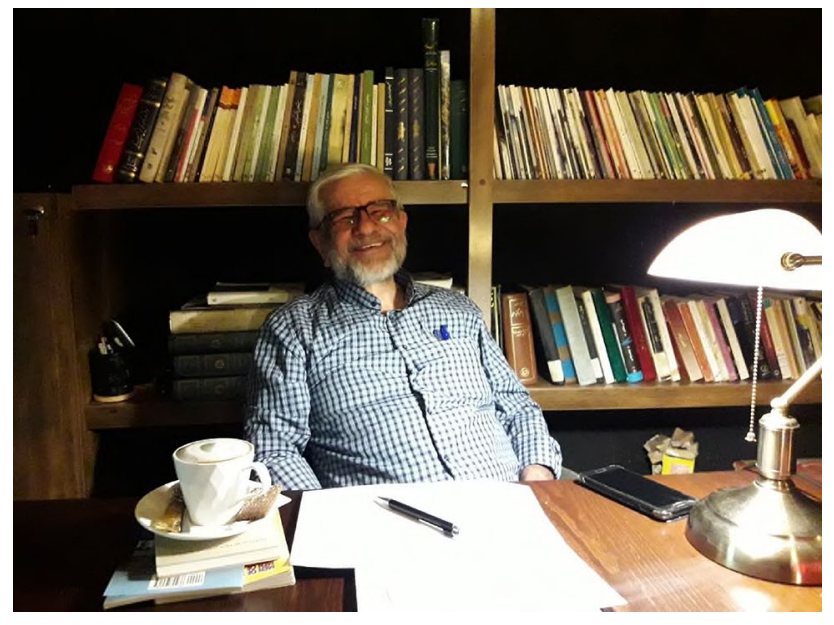

Fig. 1 Professor Abolfazl Darvizeh. Photo credit: Dr. Fatima Darvizeh

forming, dynamic powder compaction and explosive welding. He later extended his studies to biological systems. He was eager to apply engineering approaches for understanding the design of biological materials and structures. In 2011, he established the first Biomimetic Engineering research group in Iran. Abolfazl Darvizeh contributed to over 120 peer-reviewed articles and 16 textbooks in Mechanical Engineering. In recognition of his academic and scientific contributions, the Ministry of Science, Research and Technology of Iran, honored him as the Distinguished Mechanical Engineering Professor of Iran in 2006.
In addition to being a prolific researcher, Abolfazl Darvizeh was also a superb teacher. He was a kind, patient and talented teacher in the classroom, who had a great sense of the needs of his students. He sought to provide his students with a joyful journey toward learning complex engineering concepts. At any break time, he was surrounded by a large group of students, with whom he was eagerly engaged in discussions. He was a devoted supervisor to his research students, many of whom regard him as their "spiritual mentor." He not only took time to guide them through their research, but also provided them with freedom and opportunity to make their own scientific profile. Most of them remember his advice that "any challenge can be turned to an opportunity."

Abolfazl Darvizeh was certainly a dominant intellectual figure in the science and engineering community in Iran. We will always remember him as a kind, patient and optimistic mentor and, of course, as an extraordinary wise man.

Acknowledgements We would like to thank Dr. Rooholamin Darvizeh, who kindly provided information and feedback on the biography of Professor Abolfazl Darvizeh.

Publisher's Note Springer Nature remains neutral with regard to jurisdictional claims in published maps and institutional affiliations. 